This is an electronic reprint of the original article. This reprint may differ from the original in pagination and typographic detail.

\author{
Author(s): Bahl, Aileen; Pöllänen, Eija; Ismail, Khadeeja; Sipilä, Sarianna; Mikkola, Tuija; Berglund, \\ Eva; Lindqvist, Carl Mårten; Syvänen, Ann-Christine; Rantanen, Taina; Kaprio, Jaakko; \\ Kovanen, Vuokko; Ollikainen, Miina
}

Title: $\quad$ Hormone Replacement Therapy Associated White Blood Cell DNA Methylation and Gene Expression are Associated With Within-Pair Differences of Body Adiposity and Bone Mass

Year: $\quad 2015$

Version:

Please cite the original version:

Bahl, A., Pöllänen, E., Ismail, K., Sipilä, S., Mikkola, T., Berglund, E., Lindqvist, C. M., Syvänen, A.-C., Rantanen, T., Kaprio, J., Kovanen, V., \& Ollikainen, M. (2015).

Hormone Replacement Therapy Associated White Blood Cell DNA Methylation and Gene Expression are Associated With Within-Pair Differences of Body Adiposity and Bone Mass. Twin Research and Human Genetics, 18(6), 647-661.

https://doi.org/10.1017/thg.2015.82

All material supplied via JYX is protected by copyright and other intellectual property rights, and duplication or sale of all or part of any of the repository collections is not permitted, except that material may be duplicated by you for your research use or educational purposes in electronic or print form. You must obtain permission for any other use. Electronic or print copies may not be offered, whether for sale or otherwise to anyone who is not an authorised user. 


\section{Hormone replacement therapy associated white blood cell DNA methylation and gene expression are associated with within-pair differences of body adiposity and bone mass}

Running title: Estrogen associated WBC methylation and expression

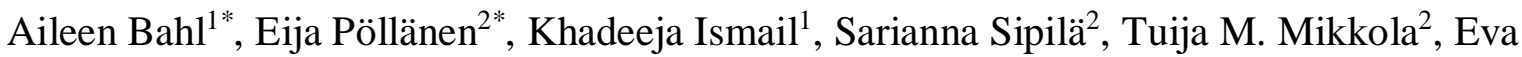
Berglund $^{3}$, Carl Mårten Lindqvist ${ }^{3}$, Ann-Christine Syvänen ${ }^{3}$, Taina Rantanen ${ }^{2}$, Jaakko Kaprio $^{1,4,5}$, Vuokko Kovanen ${ }^{2}$ and Miina Ollikainen ${ }^{1}$

${ }^{1}$ Department of Public Health, University of Helsinki, Helsinki, Finland

${ }^{2}$ Gerontology Research Center, Department of Health Sciences, University of Jyväskylä, Jyväskylä, Finland

${ }^{3}$ Department of Medical Sciences, Molecular Medicine and Science for Life Laboratory, Uppsala University, Uppsala, Sweden

${ }^{4}$ Institute for Molecular Medicine FIMM, University of Helsinki, Helsinki, Finland

${ }^{5}$ National Institute for Health and Welfare, Helsinki, Finland

* Bahl and Pöllänen equally contributed to the study.

Corresponding author:

Miina Ollikainen, $\mathrm{PhD}$

Department of Public Health,

P.O. BOX 41

FI-00014 University of Helsinki

Finland

Phone +358 294127542

Fax +358 294127570

email miina.ollikainen@helsinki.fi 


\begin{abstract}
The loss of estrogen during menopause causes changes in the female body with wide-range effects on health. Estrogen-containing hormone replacement therapy (HRT) leads to a relief of typical menopausal symptoms, benefits bone and muscle health, and associates with tissue-specific gene expression profiles. As gene expression is controlled by epigenetic factors (including DNA methylation) many of which are environmentally sensitive, it is plausible that at least part of the HRT-associated gene expression is due to changes in DNA methylation profile.
\end{abstract}

We investigated genome-wide DNA methylation and gene expression patterns of white blood cells (WBCs) and their associations with body composition, including muscle and bone measures of monozygotic female twin pairs discordant for HRT. We identified 7855 differentially methylated regions (DMRs) associated with 4044 genes. Of the genes with DMRs, five (ACBA1, CCL5, FASLG, PPP2R2B and UHRF1) were also differentially expressed. All have been previously associated with HRT or estrogenic regulation, but not with HRT-associated DNA methylation. All five genes were associated with bone mineral content, and $A B C A 1, F A S L G$ and $U H R F 1$ were also associated with body adiposity.

Our study is the first to show that HRT associates with genome-wide DNA methylation alterations in WBCs. Moreover, we show that five differentially-expressed genes with DMRs associate with clinical measures, including body fat percentage, lean body mass, bone mass, and blood lipids. Our results indicate that at least part of the known beneficial HRT effects on body composition and bone mass may be regulated by DNA methylation associated alterations in gene expression in circulating WBCs. 
Key words: hormone replacement therapy; HRT; menopause; discordant monozygotic twin pair design; gene expression; DNA methylation; epigenetic regulation; body composition, skeletal muscle composition, bone mineral content 
Menopause leads to constantly low circulating $17 \beta$-estradiol $\left(\mathrm{E}_{2}\right)$ levels compared with premenopausal cyclic monthly fluctuation of high to low systemic $\mathrm{E}_{2}$. Most commonlyexperienced adverse consequences are vasomotor symptoms such as hot flushes and night sweats, which are effectively treated with $\mathrm{E}_{2}$-based hormone replacement therapy (HRT) (Sassarini \& Lumsden, 2015). HRT has also been shown to be associated with better muscle and bone health (Mikkola et al., 2011; Ronkainen et al., 2009). Aging is typically associated with deterioration of bone properties, reduced skeletal muscle mass and increased ectopic fat accumulation, which affect muscle quality and function. $\mathrm{E}_{2}$ deprivation has been shown to result in gain of fat mass and loss of fat free mass (Shea et al., 2015) as well as in increased risk for osteoporotic changes (Riggs, Khosla, \& Melton, 2002; Szulc et al., 2006) while postmenopausal HRT partially counteracts aging related musculoskeletal deteriorations (Cheng et al., 2002; Komulainen et al., 1999; Sipilä et al., 2001; Taaffe et al., 2005). However, there is considerable variation in response to HRT between individuals, which can be partly explained by genetic factors (Langdahl, 2009).

Studying HRT discordant postmenopausal monozygotic (MZ) twins eliminates differences in the DNA sequence between HRT users and their non-user twin sisters. This enables investigation of potential epigenetic influences of HRT. The purpose of this study was to investigate the association of long-term HRT on white blood cell (WBC) DNA methylation and thereby gene expression as a potential mechanism associated with differences in total body, muscle and bone characteristics in postmenopausal MZ twin pairs discordant for $\mathrm{E}_{2}-$ based HRT use. We hypothesized that HRT-associated differences in DNA methylation could underlie gene expression differences that in turn would manifest as differences at the phenotype level. To test this hypothesis, we investigated $20 \mathrm{HRT}$ discordant MZ twin pairs for genome-wide DNA methylation and determined differentially methylated regions (DMRs) within the discordant twin pairs. Next we examined if genes with DMRs are also 
differentially expressed in WBCs in a subgroup of nine HRT discordant twin pairs. Finally, the within-pair expression differences were correlated with within-pair differences of the phenotype characteristics to further link the identified DMR and gene expression profiles with body adiposity, muscle characteristics and bone mass of the HRT discordant postmenopausal MZ twin pairs.

\section{Methods}

\section{Study design and data collection}

The participants of the current study originate from two separate twin studies, the Finnish Twin Study on Aging (FITSA) and the Sarcopenia - Skeletal Muscle Adaptation to Postmenopausal Hypogonadism and Effects of Hormone Replacement Therapy and Physical Activity in Older Women: a Genetic and Molecular Biological Study on Estrogenrelated Pathways (SAWEs), for which the subjects were recruited from the Older Finnish Twin Cohort (Kaprio et al., 1978; Kaprio \& Koskenvuo, 2002) consisting of 13888 twin pairs of known zygosity. The FITSA-study investigates the genetic and environmental effects on the disablement process in older female twins (Tiainen et al., 2004). The SAWEs-study investigates the associations of HRT on muscle properties at molecular level in the genetically controlled design (Ronkainen et al., 2009). Zygosity of all twins was confirmed by genotyping multiple polymorphic markers. Study participants visited our laboratory in two consecutive days. The evening of the first day consisted of the computed tomography assessments for muscle composition. The second day consisted of blood sampling and measurements of body and bone composition.

MZ HRT-discordant twin pairs $(n=20)$ were studied. The HRT using co-twins were on $\mathrm{E}_{2}-$ based HRT with the preparation containing either $E_{2}$ only $(n=12)$ with 1-2- mg of estrogenic agent or $E_{2}$ in combination with progesterone $(n=8)$ with estrogenic $(1-2 \mathrm{mg})$ and progestogenic compounds. The other co-twin had never used HRT. The age of the 
participants ranged from 54 to 72 years (mean age $62.4 \pm 6.0$ years). The mean duration of HRT use was $8.8 \pm 5.7$ years (range 1-25 years). Physical activity was assessed with the scale of Grimby (Grimby, 1986), with slight modifications and categorized as sedentary (no other activities, but at the most light walking 2 times/wk), moderately active (walking or other light exercise at least 3 times/wk, but no other more intensive activities), and active (moderate or vigorous exercise at least 3 times/wk) (Ronkainen et al., 2009).

The subjects provided written informed consent. The protocol was designed and performed according to the principles of the Helsinki Declaration and approved by the Ethics Committee of the Hospital District of Central Finland.

\section{Total body and muscle composition and bone mineral content}

Total body fat percentage and lean body mass were assessed by bioelectrical impedance analysis (Spectrum II, RJL Systems, Detroit, MI, USA). Computed tomography scans (Siemens Somatom motion scanner, Siemens, Erlangen, Germany) were obtained from the midpoint between the greater trochanter and the lateral joint line of the knee and analyzed with the Geanie 2.1 software (Commit, Espoo, Finland) to separate lean and fat tissue on the basis of the given radiological density limits. Total cross sectional area (CSA) of thigh muscle compartment was determined by manually outlining the muscle compartment along the fascial plane to exclude subcutaneous fat. Within this area, lean muscle CSA was further separated from inter- and intramuscular (IM) fat tissue infiltrated into the muscle compartment. As an indicator of muscle quality, the mean attenuation coefficient in Hounsfield units (HU), i.e., mean density value within lean muscle CSA was defined. Low HU values are associated with high amount of lipids infiltrating into muscle tissue therefore indicating poor muscle quality (Goodpaster et al., 2000). 
Peripheral quantitative computed tomography scans (pQCT, XCT 2000, Stratec Medizintechnik GmbH, Pforzheim, Germany) were obtained from the side of the dominant hand (Mikkola et al., 2011). The scanned sites were 5\% of the tibial length proximal to the distal end of the tibia, and in the radius $4 \%$ of the length of the forearm proximal to the distal end of radius. Bone mineral content (BMC) of a 1-mm-thick slice was analyzed using the Geanie 2.1 software and a density threshold of $130 \mathrm{mg} / \mathrm{cm}^{3}$ was used to separate bone from the surrounding soft tissue.

\section{Blood sampling and assessment of systemic hormones, lipids and CRP}

Blood samples were taken after overnight fasting and sera were stored at $-80{ }^{\circ} \mathrm{C}$ until further analyses. Serum hormone assessments were performed as previously described (Ronkainen et al., 2009). Serum $\mathrm{E}_{2}$ was determined using an extraction radioimmunoassay (Ankarberg-Lindgren \& Norjavaara, 2008). Serum concentrations of sex hormone-binding globulin (SHBG) and high sensitivity C-reactive protein (CRP) were measured using solidphase, chemiluminescent immunometric assays (Immulite 1000; Diagnostic Products, Los Angeles, CA, USA). Free $\mathrm{E}_{2}$ levels were calculated from $\mathrm{E}_{2}$ and $\mathrm{SHBG}$ levels according to (Bjornerem et al., 2004). Serum total cholesterol, low-density lipoprotein-cholesterol (LDL), high-density lipoprotein-cholesterol (HDL), and triglycerides were measured by enzymatic colorimetric assays using a KoneLab20 Clinical Chemistry Analyzer (Thermo Scientific, Vantaa, Finland).

\section{DNA extraction and methylation analysis}

High molecular weight WBC DNA was extracted using QIAamp DNA Mini kit (QIAGEN Nordic, Sollentuna, Sweden). Bisulfite conversion of DNA was completed using EZ-96 DNA Methylation-Gold Kit (Zymo Research, Irvine, CA, USA) according to the 
manufacturer's instructions, and the co-twins were always converted on the same plate to minimize potential batch effects.

Genome-wide DNA methylation of 40 twin samples (20 pairs) was measured using the Illumina Infinium HumanMethylation450 BeadChip according to the manufacturer's instructions (Illumina, San Diego, CA, USA). Data pre-processing was carried out using R $\begin{array}{lllll}\text { software } & \text { R-3.02 (http://www.R-project.org) and } \quad \text { Bioconductor } 2.13\end{array}$ (http://www.bioconductor.org), as described previously (Ollikainen et al., 2015). First, we filtered out CpG sites that did not fulfill certain quality measures. We discarded 1) probes with a detection p-value $>0.001$ in any sample $(n=2,653), 2)$ 'rs' $(n=65)$ and 'ch' $(n=3,076)$ probes reflecting SNP genotyping probes that are only included for DNA tracing and nonCpG probes (Nordlund et al., 2013; Price et al., 2013), respectively, on the 450k array, 3) unreliable probes $(\mathrm{n}=103,421)$ according to (Naeem et al., 2014), as well as 4) probes on sex chromosomes $(n=8,100)$ as differing beta values of the probes might be the result of random $\mathrm{X}$ inactivation by DNA methylation. As a final filtering step, we removed uninformative probes, i.e. $50 \%$ of probes with lowest variance $(n=184,131)$ among the studied samples.

We used $\mathrm{R}$ Bioconductor package lumi for background correction and quantile normalization of the $450 \mathrm{k}$ data. Color normalization was performed using the ASMN algorithm. Additionally, we used BMIQ from the wateRmelon package to account for differences in the distributions of the two different probe types. For removing batch effects we used ComBat function from the sva package. As neighboring $\mathrm{CpG}$ sites are known to have highly similar methylation values, we averaged over the beta values of CpG sites located in the same $\mathrm{CpG}$ island (Supplementary Figure S1). We identified the CpGs belonging to the same $\mathrm{CpG}$ island and computed the mean values of the betas for each 
individual. These CpGs thus define a region with a potential of becoming a DMR in downstream analyses. All probes not belonging to any $\mathrm{CpG}$ islands remain as singletons in the analyses. For uniformity, these probes will also be referred to as DMRs (instead of differentially methylated probes, DMPs) in case they show differential methylation in further analyses. The CpG islands were defined as in (Price et al., 2013) and Supplementary Figure S1. Briefly, high density $\mathrm{CpG}$ islands (HC) have $\mathrm{CG}$ content of $>55 \%$, the observed/expected ratio is $>0.75$, and the length of the island is $>500 \mathrm{bp}$. Intermediate density $\mathrm{CpG}$ islands (IC) have $\mathrm{CpG}$ content of $>50 \%$, the observed/expected ratio $>0.48$, and the length of the island is $>200 \mathrm{bp}$. CpGs not belonging to $\mathrm{CpG}$ islands are classified as LC CpGs (low density CpGs). The final data set consisted of 104,976 regions that were used in the analyses.

\section{RNA extraction and gene expression analysis}

WBC total RNA was extracted using Trizol reagent (Invitrogen, Carslbad, CA, USA) according to the manufacturer's protocol. RNA concentration was measured spectrophotometrically and quality determined by Experion (Bio-Rad Laboratories, Hercules, CA). Only good-quality RNA (260/280 ratio 1.8) was used in further analyses. Sentrix Human-WG6 V3 Expression BeadChip microarrays (Illumina, San Diego, CA) were used for the transcriptome-wide expression analysis as described previously (Ronkainen et al., 2010). Briefly, an Illumina RNA amplification kit (Ambion, Austin, TX) was used according to the manufacturer's instructions. Hybridization, washing and scanning steps were performed according to the Illumina Whole-Genome Gene Expression Direct Hybridization protocol (revision A). Twins of a pair were always hybridized onto the same BeadChip. The data were acquired by Bead Studio 3.1.3.0 (module v. 3.3.7, Illumina, San Diego, USA). The average signal intensity for individual genes was computed after excluding beads that fell outside three normal standard deviations of median intensity. 
Expression data was $\log 2$-transformed to stabilize the gene expression variance before quantile normalization in R Bioconductor package lumi.

\section{Statistics}

All statistical analyses were performed in R. Differential within-pair analysis of genomewide DNA methylation and candidate gene expression was performed in limma (http://bioconductor.org/packages/release/bioc/manuals/limma/man/limma.pdf). Linear regression models were applied to all methylation probes in the final data set to determine significant DMRs within twin pairs discordant for HRT. In the same way, limma was used to assess differential expression of only those genes with DMRs. Methylation and expression probes were matched based on Entrez IDs. In both analyses, the data was adjusted for smoking discordance (ever vs. never smoker) within the twin pairs. Under- or overrepresentation of DMRs in specific genomic regions or in relation to $\mathrm{CpG}$ density in comparison to the $\mathrm{CpG}$ distributions in the whole data set was assessed using Fisher's test. Global HRT associated methylation patterns were computed by categorizing each DMR as hypo- or hypermethylated in HRT users. This categorization was performed on within-pair methylation differences over all pairs. Significance of the global overrepresentation of differential methylation in one direction (global hypo- or hypermethylation at a higher rate than expected) was assessed using Binomial test. Pearson correlations between significantly differentially expressed genes with DMRs and clinical measures were computed on within-pair differences of expression values and within-pair differences of trait values. All p-values were adjusted for multiple testing using Benjamini-Hochberg procedure. Adjusted p-values $(\mathrm{FDR}) \leq 0.05$ were considered significant, if not specified otherwise. 


\section{Gene ontology analysis}

Gene ontology analysis of within-pair differential methylation was carried out using the GSA package in R. (http://statweb.stanford.edu/ tibs/ftp/GSA.pdf). Methylation probes were assigned to probe-sets representing GO terms. In order to avoid considering too small or too large and thus irrelevant GO terms, we restricted the analysis to sets with a minimum of 15 and a maximum of 500 genes. GSA was applied on within-pair methylation differences with 1,000 permutations. GO terms with FDR $<0.05$ were considered as significant. GSA does not take into account the number of $\mathrm{CpG}$ sites on individual genes in a GO term; however, there was no obvious bias related to number of probes per gene (Supplementary Figure S2).

\section{Results}

\section{Phenotypic characteristics}

General properties and metabolic measures of the HRT users and non-users belonging to the discordant twin pairs are presented in Table 1 . Their mean age was $62.4 \pm 6.0$ years. As expected, HRT users had higher mean circulating levels of total and free $\mathrm{E}_{2}$ compared to their non-user co-twins $\left(202.8 \pm 205.8\right.$ vs. $27.1 \pm 22.0 \mathrm{pmol} / \mathrm{l}, \mathrm{p}=9.6 \times 10^{-5} ; 3.5 \pm 2.9$ vs. $0.6 \pm 0.5 \mathrm{pmol} / \mathrm{l}, \mathrm{p}=9.5 \times 10^{-6}$, respectively). HRT users also had higher serum SHBG concentration than their non-using co-twins $\left(86.2 \pm 41.3\right.$ vs. $\left.55.3 \pm 27.1, \mathrm{p}=3.6 \times 10^{-5}\right)$. There was no evidence for differences in the concentrations of blood lipids and CRP between HRT users and non-users ( $\mathrm{p}>0.05$ for both). Any evidence for the differences between twins in the level of physical activity assessed by a 3-scale self-assessment score was observed $(\mathrm{p}>0.05)$. In addition, we did not observe any significant differences in WBC count estimates (Houseman et al., 2012) between HRT users vs. non-users (p > 0.05 
for all WBC estimates), which is an important point considering the downstream DNA methylation analyses that could otherwise be confounded by differences in cell type distributions.

Table 2 presents the phenotypic characteristics of HRT users and non-users. There were no evidence for differences in the body composition between the HRT users and non-users ( $p$ $>0.05)$. The more precise analysis of thigh muscle composition, which we had available from nine twin pairs, revealed no differences in the lean muscle area of thigh, the amount of subcutaneous fat surrounding thigh, intra- or intermuscular (IM) fat infiltration within thigh muscle compartment nor in the amount of IM fat assessed as the lean muscle density of thigh ( $\mathrm{p}>0.05)$. HRT users had higher BMC than their non-user co-twins, both in tibia $(274.2 \pm 35.9$ vs. $254.3 \pm 48.0, p=0.0046)$ and radius $(104.0 \pm 15.2$ vs. $96.2 \pm 20.3, p=$ $0.018)$.

[Table 1 and Table 2 about here]

\section{Genome-wide DNA methylation analysis}

Genome-wide DNA methylation analysis within the 20 HRT discordant MZ twin pairs did not result in any significant DMRs after multiple testing correction. However, 7855 DMRs with nominal p-value $\leq 0.05$ (Supplementary Table S1) were observed. DMRs were enriched at intergenic regions and depleted at gene promoters (FDR $<0.001$, Figure 1a). When investigating the location of the DMRs in relation to $\mathrm{CpG}$ density, the majority were at non-island (low density, LC) CpG sites. Consistent with this, high density CpG (HC) islands were significantly under-represented $\left(\mathrm{FDR}<3.3 \times 10^{-16}\right)$ whereas LC CpG sites were over-represented (FDR $<3.3 \times 10^{-16}$ ) among the DMRs when compared to the whole array distribution of the $\mathrm{CpG}$ sites (Figure 1b). Finally, the DMRs were more frequently 
hypomethylated than hypermethylated $\left(\mathrm{p}<2.2 \times 10^{-16}\right)$, suggesting that HRT associates with global hypomethylation.

[Figure 1 about here]

In addition to investigating individual $\mathrm{CpG}$ islands or isolated $\mathrm{CpG}$ sites, we tested whether any gene sets associating to the same biological processes, cellular components and molecular functions are differentially methylated within twin pairs. This was accomplished by assigning all the $\mathrm{CpG}$ sites across the genome to probe-sets representing GO terms and running a gene set analysis (GSA) on the full DNA methylation dataset. GSA resulted in three significantly hypomethylated and five hypermethylated GO terms (FDR $<2.2 \times 10^{-16}$, Table 3). The significant biological processes were related to regulation of translation and apoptosis, and to chemical reactions and pathways involving sphingolipids. The molecular functions were associated to signal transduction.

[Table 3 about here]

\section{Differential expression analysis of genes with DMRs}

To investigate the potential biological relevance of the identified within-pair methylation differences, we applied a hypothesis-based approach and tested whether the genes with nominally significant DMRs are differentially expressed. This analysis revealed that five genes associated with DMRs were also differentially expressed within-pairs (FDR $<0.05$, Table 4). We observed no clear uniformity between the genomic locations, CpG density and methylation status of the DMRs and the direction of the gene expression difference of the respective genes (Figure 2). The differentially expressed genes were ATP-binding cassette sub-family A member 1 ( $A B C A 1)$, chemokine (C-C motif) ligand 5 (CCL5, also known as RANTES), ubiquitin-like with PHD and ring finger domains 1 (UHRF1), protein 
phosphatase 2 regulatory subunit $\mathrm{B}(P P P 2 R 2 B)$ and Fas ligand (TNF superfamily member 6, FASLG), and they function in apoptosis and cell survival (FASLG [Zhang et al., 2009] and PPP2R2B [Paluszczak et al., 2014]), transcription and epigenetic regulation (UHRF1 [Berkyurek et al., 2014]), immunoregulation (CCL5 [Viola \& Luster, 2008]), and in cellular cholesterol removal and assembly of HDL (ABCA1 [Schmitz \& Langmann, 2001]).

[Table 4 and Figure 2 about here]

\section{Correlation of the expression of genes with DMRs with clinical measures of the HRT discordant twin pairs}

In an attempt to understand how the differentially expressed genes with DMRs ( $A B C A 1$, CCL5, UHRF1, PP2R2B and FASLG) link to the clinical outcomes, we correlated the within-pair gene expression differences with the within-pair differences of the relevant clinical measures. The observed strong correlations between the within-pair differences in serum concentration of both total and free $\mathrm{E}_{2}$ with the within-pair difference in gene expression of each of the identified five genes supported the hypothesis that these genes are targets for HRT-mediated regulation (Figure 3 and Supplementary Table S2). Negative association was found for $A B C A 1\left(\mathrm{r}=-0.92, \mathrm{FDR}=8.63 \times 10^{-4}\right)$ and $U H R F 1(\mathrm{r}=-0.90, \mathrm{FDR}$ $\left.=1.18 \times 10^{-3}\right)$ and positive association with FASLG $\left(\mathrm{r}=0.85, \mathrm{FDR}=3.56 \times 10^{-3}\right)$, CCL5 $(\mathrm{r}=$ $\left.0.94, \mathrm{FDR}=4.79 \times 10^{-4}\right)$ and $P P P 2 R 2 B\left(\mathrm{r}=0.94, \mathrm{FDR}=4.79 \times 10^{-4}\right)$. When we investigated the associations for blood lipids, all the five genes were highly correlated with triglycerides and all but one gene (UHRF1) with LDL (Figure 3 and Supplementary Table S2). We also analyzed the associations between the within-pair differences of ABCA1, UHRF1, FASLG, $C C L 5$ and $P P P 2 R 2 B$ expression, and body composition (Figure 3 and Supplementary Table S2). $A B C A 1$ was negatively and $F A S L G$ and $P P P 2 R 2 B$ positively correlated with lean body mass, and $A B C A 1$ and $U H R F 1$ were negatively and $F A S L G$ positively correlated with body 
fat percentage, indicating that these genes associate with total body composition in $\mathrm{HRT} / \mathrm{E}_{2}$ related manner. In order to determine more precisely the nature of this association between gene expression and lean vs. fat mass, we did correlation analysis with the available variables of lean mass (lean muscle CSA of thigh, distal tibia BMC and distal radius BMC) and fat mass (IM fat within muscle compartment and lean muscle density of thigh and subcutaneous fat surrounding thigh). There were no significant associations between gene expression and thigh fat variables i.e. IM fat, muscle density and subcutaneous fat, and only borderline significance between gene expression and lean muscle CSA (FDR for association between lean muscle CSA and $A B C A 1$ expression was 0.058 and $>0.6$ for UHRF1, CCL5, PPP2R2B and FASLG, Supplementary Table S2). However, lower leg and arm BMC (distal tibia and distal radius, respectively) was highly significantly associated with expression of all five genes (Figure 3 and Supplementary Table S2).

[Figure 3 about here]

\section{Discussion}

In the current study we report associations of postmenopausal HRT with genome-wide DNA methylation and gene expression in WBCs by investigating HRT-discordant MZ twin pairs. Through within-pair genome-wide DNA methylation analysis we identified a number of genes with HRT-associated DMRs, of which five were differentially expressed. $A B C A 1$ and UHRF1 were down-regulated whereas CCL5, PPP2R2B and FASLG were up-regulated in WBCs of the HRT users compared with their genetically identical non-user twin sisters. Linking our gene level findings to clinical phenotype measures showed that total body composition, bone mass and blood lipids strongly associate with the differentially expressed genes with DMRs. These data indicate that at least part of the known beneficial 
HRT effects on the clinical outcomes may be regulated by DNA methylation in circulating WBCs.

Alterations in DNA methylation, both at global and individual gene level, have long been shown to associate with many human diseases, such as cancer (Lin \& Wagner, 2015; Stefansson et al., 2015), type 2 diabetes (Nilsson et al., 2014), BMI (Dick et al., 2014), and obesity-associated metabolic disturbances (Ollikainen et al., 2015), as well as aging (Marttila et al., 2015; Yuan et al., 2015). However, to our knowledge, there are no genomewide methylation studies on the effects of HRT. One previous study has shown that conjugated equine estrogen therapy is associated with reduced plasma homocysteine and increment of total level of genomic methylation in peripheral mononuclear cells (Friso et al., 2007). We, however, identified 7855 DMRs with nominal significance and global DNA hypomethylation in WBCs associated with HRT. This potential discrepancy may be partially explained by differences in HRT specimen (equine estrogen vs. estradiol). In our study, the genomic distribution of the DMRs in relation to genes and $\mathrm{CpG}$ density was highly similar to what has been previously reported for complex diseases; gene promoters and $\mathrm{HC}$ islands were under-represented and intragenic regions and LC CpGs overrepresented among DMRs compared to the whole array distribution of the CpG sites (Irizarry et al., 2009; Nilsson et al., 2014; Ollikainen et al., 2015; Yang et al., 2015). Hence, HRT seems to affect DNA methylation in similar genomic regions as reported for common multifactorial diseases. As most of the complex diseases are age-related, it is possible that at least part of these commonly observed associations between DNA methylation and different diseases are due to aging-associated methylation changes, including global hypomethylation (Heyn et al., 2012; Johansson, Enroth, \& Gyllensten, 2013; Yuan et al., 2015). As our study is based on within-pair comparisons of HRT-discordant MZ twin pairs, the effect of age could potentially only manifest as increased methylation variation by age, 
as reported previously for unrelated individuals (Tserel et al., 2015). Also, the age-range that we studied was relatively limited, so we cannot draw conclusions about very old women, or premenopausal women.

In addition to investigating individual $\mathrm{CpG}$ islands and isolated $\mathrm{CpG}$ sites, we also examined DNA methylation in gene sets to detect HRT associated differential methylation clustering to gene ontologies. Interestingly, all hypomethylated GOs associated with cell survival and apoptosis, and hypermethylated GOs with neural function related GOs. Both of these larger entities are highly relevant for HRT. Estrogen has been shown to regulate cell proliferation and apoptosis (Fang et al., 2015), and to increase cognitive abilities and other brain functions (Comasco, Frokjaer, \& Sundstrom-Poromaa, 2014; Mahmutyazicioglu et al., 2014). Dysfunction of the olfactory system is an early sign of neurodegeneration, and HRT has a positive effect on olfactory function (Doty et al., 2015), explaining our GO findings related to sensory perception of smell and olfactory receptor activity. Unfortunately, in the current study we did not assess cognition or other neural functions. Therefore further studies are needed to see if the HRT associated methylation and gene expression indeed have a role in neural function.

In order to go beyond only reporting associations on genome-wide DNA methylation we investigated the potential biological relevance of the identified within-pair methylation differences by exploring whether any of the genes with DMRs are differentially expressed. This analysis revealed that five genes with DMRs (ABCA1, UHRF1, FASLG, PPP2R2B and CCL5) were also differentially expressed within-pairs, and showed that the relationships between gene body or promoter methylation and gene expression are widespread, as previously reported (Wagner et al., 2014). ABCA1, CCL5 and FASLG have been previously shown to associate with HRT and menopause (Christodoulakos et al., 
2007; Darabi, Rabbani et al., 2011; Kangas et al., 2014), and both UHRF1 and PPP2R2B have been associated to estrogen related breast cancer by epigenetic mechanisms (Jin et al., 2010; Klajic et al., 2013; Muggerud et al., 2010). In addition, $P P P 2 R 2 B$ is a member of a PP2-family, whose expression levels have been reported to be maintained by estrogen (Yi \& Simpkins, 2008). Moreover this family is directly involved in synaptic plasticity and memory formation. In addition, FASLG may also play a role in neuroprotection (Knight, Scharf, \& Mao-Draayer, 2010). This goes nicely hand in hand with our GO findings, and thus increased expression and differential methylation of $P P P 2 R 2 B$ and FASLG in HRT users in our study further support the potential neuroprotective role of HRT.

As an attempt to understand the clinical relevance of our DNA methylation and gene expression findings we correlated the expression of the DMR-containing genes with clinical measures obtained from the HRT discordant twin pairs (Figure 3, Supplementary Table S2). This analysis revealed three distinct clusters. First, both measures of total body size, body fat percentage and lean and body mass, were in the same cluster with serum $\mathrm{E}_{2}$ sharing the direction of the association with gene expression. ABCAl and UHRFI was negatively and FASLG, PPP2R2B and CCL5 positively associated with $\mathrm{E}_{2}$ and total body size. Second, triglycerides shared the association pattern with BMC measures. $A B C A 1$ and FASLG expression was negatively while UHRF1, PPP2R2B and CCL5 expression was positively associated with triglycerides and BMC. The third cluster was formed by the cholesterol measures, of which only LDL showed significant association with gene expression. $A B C A 1$ and FASLG expression was positively while $P P P 2 R 2 B$ and $C C L 5$ negatively associated with LDL concentration.

Our findings support the known influence of HRT on whole body lipid levels. Individuals on HRT generally show higher HDL and apoA levels while LDL cholesterol and apoB 
levels are usually decreased (Darabi et al., 2011). $A B C A 1$, which we found to be differentially expressed and methylated, is a specialized transmembrane receptor of peripheral cells involved in the reverse cholesterol process mediating cholesterol efflux to HDL particles. Some studies have shown HRT to increase $A B C A 1$ gene expression (Darabi, Ani et al., 2011; Darabi et al., 2011), while others including our current study have observed decreased $A B C A 1$ levels due to HRT (Cerda et al., 2013). We did not observe differences in blood lipids within HRT user and non-user twin pairs, possibly due to the fact that genetic regulation is stronger determinant of blood lipid concentrations than the effects of HRT. However, within-pair difference in $A B C A 1$ expression was strongly positively correlated with within-pair difference in LDL and negatively with within-pair difference in triglycerides. $A B C A 1$ mediated reverse cholesterol transport has also been linked to inflammation and apoptosis of WBCs (Mineo \& Shaul, 2012).

As another indicator of the association of HRT with inflammation we found two inflammatory cytokines $C C L 5$ and $F A S L G$ to be differentially expressed and methylated. FASLG also removes monocytes after the immune response by inducing their apoptosis (Mor et al., 2003; Perlman et al., 2001). Thus, higher FASLG expression may participate in prevention of inflammation.

Estrogen-mediated upregulation of $F A S L G$ has also been shown to be important in maintaining bone remodeling balance (Shao et al., 2015; Wang et al., 2015). Although DNA methylation has been previously proposed as a regulatory mechanism of FASLG expression (Castellano et al., 2006), HRT has not been suggested to be inductor of its differential methylation before. Our study shows that FASLG has LC type DMR in the gene promoter area, is differentially expressed, and moreover, that its expression is significantly associated with distal tibia and radius BMC. Thus, these data support the role of estrogen as 
a regulator of FASLG expression and further suggest methylation as a mediating mechanism of the regulation.

Finally, our results support the role of HRT in maintaining healthier body composition. Main contributors to lean body mass are lean muscle mass and bone mass. Of these, we assessed muscle mass as thigh lean muscle CSA and bone mass as the BMC of tibia and radius, and found bone variables to negatively associate with the expression of $A B C A 1$ and FASLG and positively with the expression of UHRF1, PPP2R2B and CCL5. Another important body composition measure is fat percentage that is a measure of total body adiposity including both abdominal subcutaneous and visceral adipose tissue as well as peripheral gluteofemoral and intramuscular adipose tissue. Since abdominal and gluteofemoral adipose tissue has been shown to possess opposite roles in metabolic health (Manolopoulos, Karpe, \& Frayn, 2010), we examined the associations between gene expression and thigh subcutaneous and IM fat, as rough estimates of gluteofemoral fat, but found no significant correlations. However, total body fat percentage correlated negatively with $A B C A 1$ and $U H R F 1$, and positively with $F A S L G$ expression. This observation may indicate that these associations largely come from abdominal fat depots. Therefore, we can conclude that the identified differentially expressed and methylated genes are involved in HRT associated regulation of body composition, however, without further studies it is difficult to determine how clinically relevant these associations are.

We used WBCs as a target tissue for HRT-associated DNA methylation. A limitation of using such tissue consisting of multiple cell types is that the observed DNA methylation and gene expression profiles may reflect differences in the cell type compositions between HRT users and non-users, especially as aging is associated with increased inflammation and HRT with reduced inflammation. However, we did not observe any differences in the 
estimated cell type distributions within the HRT discordant twin pairs. In addition, all WBC types are similarly in close contact with and predisposed to the systemic estradiol concentration. Since DNA methylation is tissue specific, it can be speculated that the associations between gene expression of the genes with DMRs and the body composition measures of muscle, bone and fat could be stronger if DNA methylation and gene expression were measured in the respective tissues. Therefore, future studies are needed to see if any of our findings in WBCs can be replicated in other important estrogen target tissues, such as muscle, bone and adipose tissue of HRT users vs non-users. Furthermore, we cannot exclude the possibility that our HRT-discordant co-twins are also discordant for some other factors influencing their experience or coping strategy on the physiological menopausal symptoms, leading to the discordance in HRT use. If such a factor affects DNA methylation in WBCs it could, at least in theory, confound our results. No previous DNA methylation studies in relation to menopausal symptoms or factors influencing the decision to start using HRT exist. Although precaution in interpreting our results is warranted, we are confident that our observations are due to HRT-discordance associated differences in circulating estradiol concentrations rather than due to other factors related to HRT.

To conclude, our study is the first attempt to associate postmenopausal HRT use with genome-wide DNA methylation and associated differences in gene expression of WBCs. Our results suggest that HRT-associated methylation associated with differential gene expression may be one of the biological mechanisms driving beneficial HRT effects on body adiposity and bone mass. However, further studies are needed to evaluate and confirm the clinical relevance of our findings. 


\section{Acknowledgements}

We thank the participants for their invaluable contributions to the study. The technical staffs at the Finnish Twin Cohort Study and at the Department of Health Sciences and Gerontology Research Center at University of Jyväskylä are acknowledged for their help in collecting the data. Gerontology Research Center is a joint effort between the University of Jyväskylä and the University of Tampere. The 450k DNA methylation analysis was performed by the SNP\&SEQ Technology Platform in Uppsala, which is part of the National Genomics Infrastructure hosted by Science for Life Laboratory.

\section{Financial support}

This study was supported by the Academy of Finland (M.O., grant number 251316 V.K., grant number 114310, J.K., grant numbers 265240 and 263278, T.R., grant number 69818), Finnish Ministry of Culture and Education (V.K., grant number 89/627/2008, T.R., grant number 120/722/2003), The Sigrid Juselius Foundation (M.O.); EPITRAIN - Innovative techniques and models to understand epigenetic regulation in the pathogenesis of common diseases (J.K. and M.O., EPITRAIN - FP7-PEOPLE-2012-ITN, grant number 316758); ENGAGE,- European Network for Genetic and Genomic Epidemiology, (FP7-HEALTHF4-2007, grant number 201413); the Swedish Research Council (A-C.S., grant number E0226301, C0524801); the Swedish Cancer Society (A-CS., grant number 140581) the Swedish Childhood Cancer Foundation (A-C.S., grant number PR2014-0100), the Swedish Foundation for Strategic Research (A-C.S., grant number RBc08-008); the Erik, Karin and Gösta Selander’s Stiftelse (E.B.).

\section{Conflict of interest}

None. 


\section{Ethical standards}

The authors assert that all procedures contributing to this work comply with the ethical standards of the relevant national and institutional committees on human experimentation and with the Helsinki Declaration of 1975, as revised in 2008.

\section{References}

Ankarberg-Lindgren, C., \& Norjavaara, E. (2008). A purification step prior to commercial sensitive immunoassay is necessary to achieve clinical usefulness when quantifying serum 17 beta-estradiol in prepubertal children. European Journal of Endocrinology / European Federation of Endocrine Societies, 158(1), 117-124. doi:10.1530/EJE-070403 [doi]

Berkyurek, A. C., Suetake, I., Arita, K., Takeshita, K., Nakagawa, A., Shirakawa, M., \& Tajima, S. (2014). The DNA methyltransferase Dnmt1 directly interacts with the SET and RING finger-associated (SRA) domain of the multifunctional protein Uhrf1 to facilitate accession of the catalytic center to hemi-methylated DNA. The Journal of Biological Chemistry, 289(1), 379-386. doi:10.1074/jbc.M113.523209 [doi]

Bjornerem, A., Straume, B., Midtby, M., Fonnebo, V., Sundsfjord, J., Svartberg, J., . . . Berntsen, G. K. (2004). Endogenous sex hormones in relation to age, sex, lifestyle factors, and chronic diseases in a general population: The tromso study. The Journal of Clinical Endocrinology and Metabolism, 89(12), 6039-6047. doi:89/12/6039 [pii]

Castellano, R., Vire, B., Pion, M., Quivy, V., Olive, D., Hirsch, I., . . Collette, Y. (2006). Active transcription of the human FASL/CD95L/TNFSF6 promoter region in $\mathrm{T}$ lymphocytes involves chromatin remodeling: Role of DNA methylation and protein 
acetylation suggest distinct mechanisms of transcriptional repression. The Journal of Biological Chemistry, 281(21), 14719-14728. doi:M602373200 [pii]

Cerda, A., Issa, M. H., Genvigir, F. D., Rohde, C. B., Cavalli, S. A., Bertolami, M. C., . . Hirata, R. D. (2013). Atorvastatin and hormone therapy influence expression of ABCA1, APOA1 and SCARB1 in mononuclear cells from hypercholesterolemic postmenopausal women. The Journal of Steroid Biochemistry and Molecular Biology, 138, 403-409. doi:10.1016/j.jsbmb.2013.08.017 [doi]

Cheng, S., Sipilä, S., Taaffe, D. R., Puolakka, J., \& Suominen, H. (2002). Change in bone mass distribution induced by hormone replacement therapy and high-impact physical exercise in post-menopausal women. Bone, 31(1), 126-135. doi:S8756328202007949 [pii]

Christodoulakos, G. E., Lambrinoudaki, I. V., Economou, E. V., Papadias, C., Vitoratos, N., Panoulis, C. P., . . Creatsas, G. C. (2007). Circulating chemoattractants RANTES, negatively related to endogenous androgens, and MCP-1 are differentially suppressed by hormone therapy and raloxifene. Atherosclerosis, 193(1), 142-150. doi:S00219150(06)00330-3 [pii]

Comasco, E., Frokjaer, V. G., \& Sundstrom-Poromaa, I. (2014). Functional and molecular neuroimaging of menopause and hormone replacement therapy. Frontiers in Neuroscience, 8, 388. doi:10.3389/fnins.2014.00388 [doi]

Darabi, M., Ani, M., Panjehpour, M., Rabbani, M., Movahedian, A., \& Zarean, E. (2011). Effect of estrogen receptor beta A1730G polymorphism on ABCA1 gene expression response to postmenopausal hormone replacement therapy. Genetic Testing and Molecular Biomarkers, 15(1-2), 11-15. doi:10.1089/gtmb.2010.0106 [doi] 
Darabi, M., Rabbani, M., Ani, M., Zarean, E., Panjehpour, M., \& Movahedian, A. (2011). Increased leukocyte $\mathrm{ABCA} 1$ gene expression in post-menopausal women on hormone replacement therapy. Gynecological Endocrinology: The Official Journal of the International Society of Gynecological Endocrinology, 27(9), 701-705. doi:10.3109/09513590.2010.507826 [doi]

Dick, K. J., Nelson, C. P., Tsaprouni, L., Sandling, J. K., Aissi, D., Wahl, S., . . Samani, N. J. (2014). DNA methylation and body-mass index: A genome-wide analysis. Lancet, 383(9933), 1990-1998. doi:10.1016/S0140-6736(13)62674-4 [doi]

Doty, R. L., Tourbier, I., Ng, V., Neff, J., Armstrong, D., Battistini, M., . . Sondheimer, S. J. (2015). Influences of hormone replacement therapy on olfactory and cognitive function in postmenopausal women. Neurobiology of Aging, 36(6), 2053-2059. doi:10.1016/j.neurobiolaging.2015.02.028 [doi]

Fang, D., Yang, H., Lin, J., Teng, Y., Jiang, Y., Chen, J., \& Li, Y. (2015). 17beta-estradiol regulates cell proliferation, colony formation, migration, invasion and promotes apoptosis by upregulating miR-9 and thus degrades MALAT-1 in osteosarcoma cell MG-63 in an estrogen receptor-independent manner. Biochemical and Biophysical Research Communications, 457(4), 500-506. doi:10.1016/j.bbrc.2014.12.114 [doi]

Friso, S., Lamon-Fava, S., Jang, H., Schaefer, E. J., Corrocher, R., \& Choi, S. W. (2007). Oestrogen replacement therapy reduces total plasma homocysteine and enhances genomic DNA methylation in postmenopausal women. The British Journal of Nutrition, 97(4), 617-621. doi:S0007114507433013 [pii] 
Goodpaster, B. H., Kelley, D. E., Thaete, F. L., He, J., \& Ross, R. (2000). Skeletal muscle attenuation determined by computed tomography is associated with skeletal muscle lipid content. Journal of Applied Physiology (Bethesda, Md.: 1985), 89(1), 104-110.

Grimby, G. (1986). Physical activity and muscle training in the elderly. Acta Medica Scandinavica.Supplementum, 711, 233-237.

Heyn, H., Li, N., Ferreira, H. J., Moran, S., Pisano, D. G., Gomez, A., . . Esteller, M. (2012). Distinct DNA methylomes of newborns and centenarians. Proceedings of the National Academy of Sciences of the United States of America, 109(26), 10522-10527. doi:10.1073/pnas.1120658109 [doi]

Houseman, E. A., Accomando, W. P., Koestler, D. C., Christensen, B. C., Marsit, C. J., Nelson, H. H., . . Kelsey, K. T. (2012). DNA methylation arrays as surrogate measures of cell mixture distribution. BMC Bioinformatics, 13, 86-2105-13-86. doi:10.1186/1471-2105-13-86; 10.1186/1471-2105-13-86

Irizarry, R. A., Ladd-Acosta, C., Wen, B., Wu, Z., Montano, C., Onyango, P., . . . Feinberg, A. P. (2009). The human colon cancer methylome shows similar hypo- and hypermethylation at conserved tissue-specific CpG island shores. Nature Genetics, 41(2), 178-186. doi:10.1038/ng.298 [doi]

Jin, W., Chen, L., Chen, Y., Xu, S. G., Di, G. H., Yin, W. J., . . Shao, Z. M. (2010). UHRF1 is associated with epigenetic silencing of BRCA1 in sporadic breast cancer. Breast Cancer Research and Treatment, 123(2), 359-373. doi:10.1007/s10549-0090652-2 [doi] 
Johansson, A., Enroth, S., \& Gyllensten, U. (2013). Continuous aging of the human DNA methylome throughout the human lifespan. PloS One, 8(6), e67378. doi:10.1371/journal.pone.0067378 [doi]

Kangas, R., Pöllänen, E., Rippo, M. R., Lanzarini, C., Prattichizzo, F., Niskala, P., . . Kovanen, V. (2014). Circulating miR-21, miR-146a and fas ligand respond to postmenopausal estrogen-based hormone replacement therapy--a study with monozygotic twin pairs. Mechanisms of Ageing and Development, 143-144, 1-8. doi:10.1016/j.mad.2014.11.001 [doi]

Kaprio, J., \& Koskenvuo, M. (2002). Genetic and environmental factors in complex diseases: The older finnish twin cohort. Twin Research: The Official Journal of the International Society for Twin Studies, 5(5), 358-365.

doi:10.1375/136905202320906093

Kaprio, J., Sarna, S., Koskenvuo, M., \& Rantasalo, I. (1978). The finnish twin registry: Formation and compilation, questionnaire study, zygosity determination procedures, and research program. Progress in Clinical and Biological Research, 24 Pt B, 179184.

Klajic, J., Fleischer, T., Dejeux, E., Edvardsen, H., Warnberg, F., Bukholm, I., . . . Kristensen, V. N. (2013). Quantitative DNA methylation analyses reveal stage dependent DNA methylation and association to clinico-pathological factors in breast tumors. BMC Cancer, 13, 456-2407-13-456. doi:10.1186/1471-2407-13-456 [doi]

Knight, J. C., Scharf, E. L., \& Mao-Draayer, Y. (2010). Fas activation increases neural progenitor cell survival. Journal of Neuroscience Research, 88(4), 746-757. doi:10.1002/jnr.22253 [doi] 
Komulainen, M., Kroger, H., Tuppurainen, M. T., Heikkinen, A. M., Alhava, E., Honkanen, R., .. . Saarikoski, S. (1999). Prevention of femoral and lumbar bone loss with hormone replacement therapy and vitamin D3 in early postmenopausal women: A population-based 5-year randomized trial. The Journal of Clinical Endocrinology and Metabolism, 84(2), 546-552. doi:10.1210/jcem.84.2.5496 [doi]

Langdahl, B. L. (2009). The genetics of response to estrogen treatment. Clinical Cases in Mineral and Bone Metabolism : The Official Journal of the Italian Society of Osteoporosis, Mineral Metabolism, and Skeletal Diseases, 6(1), 44-49.

Lin, Q., \& Wagner, W. (2015). Epigenetic aging signatures are coherently modified in cancer. PLoS Genetics, 11(6), e1005334. doi:10.1371/journal.pgen.1005334 [doi]

Mahmutyazicioglu, K., Besir, F. H., Bardakci, M., Tanriverdi, H. A., \& Ankarali, H. (2014). Hormone replacement therapy-related changes in the early postmenopausal period (critical window): An in vivo brain proton magnetic resonance spectroscopy study. Turkish Journal of Medical Sciences, 44(5), 853-861.

Manolopoulos, K. N., Karpe, F., \& Frayn, K. N. (2010). Gluteofemoral body fat as a determinant of metabolic health. International Journal of Obesity (2005), 34(6), 949959. doi:10.1038/ijo.2009.286 [doi]

Marttila, S., Kananen, L., Hayrynen, S., Jylhava, J., Nevalainen, T., Hervonen, A., . . Hurme, M. (2015). Ageing-associated changes in the human DNA methylome: Genomic locations and effects on gene expression. BMC Genomics, 16, 179-015-1381Z. doi:10.1186/s12864-015-1381-z [doi] 
Mikkola, T. M., Heinonen, A., Kovanen, V., Cheng, S., Kujala, U. M., Suominen, H., .. . Sipilä, S. (2011). Influence of long-term postmenopausal hormone-replacement therapy on estimated structural bone strength: A study in discordant monozygotic twins. Journal of Bone and Mineral Research : The Official Journal of the American Society for Bone and Mineral Research, 26(3), 546-552. doi:10.1002/jbmr.255 [doi]

Mineo, C., \& Shaul, P. W. (2012). Novel biological functions of high-density lipoprotein cholesterol. Circulation Research, 111(8), 1079-1090. doi:111/8/1079 [pii]

Mor, G., Sapi, E., Abrahams, V. M., Rutherford, T., Song, J., Hao, X. Y., . . Kohen, F. (2003). Interaction of the estrogen receptors with the fas ligand promoter in human monocytes. Journal of Immunology (Baltimore, Md.: 1950), 170(1), 114-122.

Muggerud, A. A., Ronneberg, J. A., Warnberg, F., Botling, J., Busato, F., Jovanovic, J., . . Tost, J. (2010). Frequent aberrant DNA methylation of ABCB1, FOXC1, PPP2R2B and PTEN in ductal carcinoma in situ and early invasive breast cancer. Breast Cancer Research : BCR, 12(1), R3. doi:10.1186/bcr2466 [doi]

Naeem, H., Wong, N. C., Chatterton, Z., Hong, M. K., Pedersen, J. S., Corcoran, N. M., . . . Macintyre, G. (2014). Reducing the risk of false discovery enabling identification of biologically significant genome-wide methylation status using the HumanMethylation450 array. BMC Genomics, 15, 51-2164-15-51. doi:10.1186/14712164-15-51 [doi]

Nilsson, E., Jansson, P. A., Perfilyev, A., Volkov, P., Pedersen, M., Svensson, M. K., . . Ling, C. (2014). Altered DNA methylation and differential expression of genes influencing metabolism and inflammation in adipose tissue from subjects with type 2 diabetes. Diabetes, 63(9), 2962-2976. doi:10.2337/db13-1459 [doi] 
Nordlund, J., Backlin, C. L., Wahlberg, P., Busche, S., Berglund, E. C., Eloranta, M. L., .. . Syvanen, A. C. (2013). Genome-wide signatures of differential DNA methylation in pediatric acute lymphoblastic leukemia. Genome Biology, 14(9), r105-2013-14-9-r105. doi:10.1186/gb-2013-14-9-r105 [doi]

Ollikainen, M., Ismail, K., Gervin, K., Kyllonen, A., Hakkarainen, A., Lundbom, J., . . . Kaprio, J. (2015). Genome-wide blood DNA methylation alterations at regulatory elements and heterochromatic regions in monozygotic twins discordant for obesity and liver fat. Clinical Epigenetics, 7(1), 39-015-0073-5. eCollection 2015. doi:10.1186/s13148-015-0073-5 [doi]

Paluszczak, J., Hemmerling, D., Kostrzewska-Poczekaj, M., Jarmuz-Szymczak, M., Grenman, R., Wierzbicka, M., \& Baer-Dubowska, W. (2014). Frequent hypermethylation of WNT pathway genes in laryngeal squamous cell carcinomas. Journal of Oral Pathology \& Medicine : Official Publication of the International Association of Oral Pathologists and the American Academy of Oral Pathology, 43(9), 652-657. doi:10.1111/jop.12178 [doi]

Perlman, H., Pagliari, L. J., Nguyen, N., Bradley, K., Liu, H., \& Pope, R. M. (2001). The fas-FasL death receptor and PI3K pathways independently regulate monocyte homeostasis. European Journal of Immunology, 31(8), 2421-2430. doi:10.1002/15214141(200108)31:8<2421::AID-IMMU2421>3.0.CO;2-W [pii]

Price, M. E., Cotton, A. M., Lam, L. L., Farre, P., Emberly, E., Brown, C. J., . . Kobor, M. S. (2013). Additional annotation enhances potential for biologically-relevant analysis of the illumina infinium HumanMethylation450 BeadChip array. Epigenetics \& Chromatin, 6(1), 4-8935-6-4. doi:10.1186/1756-8935-6-4 [doi] 
Riggs, B. L., Khosla, S., \& Melton, L. J.,3rd. (2002). Sex steroids and the construction and conservation of the adult skeleton. Endocrine Reviews, 23(3), 279-302. doi:10.1210/edrv.23.3.0465 [doi]

Ronkainen, P. H., Kovanen, V., Alen, M., Pöllänen, E., Palonen, E. M., AnkarbergLindgren, C., . . S Sipilä, S. (2009). Postmenopausal hormone replacement therapy modifies skeletal muscle composition and function: A study with monozygotic twin pairs. Journal of Applied Physiology (Bethesda, Md.: 1985), 107(1), 25-33. doi:10.1152/japplphysiol.91518.2008 [doi]

Ronkainen, P. H., Pöllänen, E., Alen, M., Pitkanen, R., Puolakka, J., Kujala, U. M., . . Kovanen, V. (2010). Global gene expression profiles in skeletal muscle of monozygotic female twins discordant for hormone replacement therapy. Aging Cell, 9(6), 1098-1110. doi:10.1111/j.1474-9726.2010.00636.x [doi]

Sassarini, J., \& Lumsden, M. A. (2015). Oestrogen replacement in postmenopausal women. Age and Ageing, 44(4), 551-558. doi:10.1093/ageing/afv069 [doi]

Schmitz, G., \& Langmann, T. (2001). Structure, function and regulation of the ABC1 gene product. Current Opinion in Lipidology, 12(2), 129-140.

Shao, B., Liao, L., Yu, Y., Shuai, Y., Su, X., Jing, H., . . Jin, Y. (2015). Estrogen preserves fas ligand levels by inhibiting microRNA-181a in bone marrow-derived mesenchymal stem cells to maintain bone remodeling balance. FASEB Journal : Official Publication of the Federation of American Societies for Experimental Biology, 29(9), 3935-3944. doi:10.1096/fj.15-272823 [doi] 
Shea, K. L., Gavin, K. M., Melanson, E. L., Gibbons, E., Stavros, A., Wolfe, P., . . Kohrt, W. M. (2015). Body composition and bone mineral density after ovarian hormone suppression with or without estradiol treatment. Menopause (New York, N.Y.), doi:10.1097/GME.0000000000000430 [doi]

Sipilä, S., Taaffe, D. R., Cheng, S., Puolakka, J., Toivanen, J., \& Suominen, H. (2001). Effects of hormone replacement therapy and high-impact physical exercise on skeletal muscle in post-menopausal women: A randomized placebo-controlled study. Clinical Science (London, England: 1979), 101(2), 147-157.

Stefansson, O. A., Moran, S., Gomez, A., Sayols, S., Arribas-Jorba, C., Sandoval, J., . . Esteller, M. (2015). A DNA methylation-based definition of biologically distinct breast cancer subtypes. Molecular Oncology, 9(3), 555-568.

doi:10.1016/j.molonc.2014.10.012 [doi]

Szulc, P., Seeman, E., Duboeuf, F., Sornay-Rendu, E., \& Delmas, P. D. (2006). Bone fragility: Failure of periosteal apposition to compensate for increased endocortical resorption in postmenopausal women. Journal of Bone and Mineral Research : The Official Journal of the American Society for Bone and Mineral Research, 21(12), 1856-1863. doi:10.1359/jbmr.060904 [doi]

Taaffe, D. R., Sipilä, S., Cheng, S., Puolakka, J., Toivanen, J., \& Suominen, H. (2005). The effect of hormone replacement therapy and/or exercise on skeletal muscle attenuation in postmenopausal women: A yearlong intervention. Clinical Physiology and Functional Imaging, 25(5), 297-304. doi:CPF628 [pii]

Tiainen, K., Sipilä, S., Alen, M., Heikkinen, E., Kaprio, J., Koskenvuo, M., . . Rantanen, T. (2004). Heritability of maximal isometric muscle strength in older female twins. 
Journal of Applied Physiology (Bethesda, Md.: 1985), 96(1), 173-180.

doi:10.1152/japplphysiol.00200.2003 [doi]

Tserel, L., Kolde, R., Limbach, M., Tretyakov, K., Kasela, S., Kisand, K., . . Peterson, P. (2015). Age-related profiling of DNA methylation in CD8+ T cells reveals changes in immune response and transcriptional regulator genes. Scientific Reports, 5, 13107. doi:10.1038/srep13107 [doi]

Viola, A., \& Luster, A. D. (2008). Chemokines and their receptors: Drug targets in immunity and inflammation. Annual Review of Pharmacology and Toxicology, 48, 171-197. doi:10.1146/annurev.pharmtox.48.121806.154841 [doi]

Wagner, J. R., Busche, S., Ge, B., Kwan, T., Pastinen, T., \& Blanchette, M. (2014). The relationship between DNA methylation, genetic and expression inter-individual variation in untransformed human fibroblasts. Genome Biology, 15(2), R37-2014-15-2r37. doi:10.1186/gb-2014-15-2-r37 [doi]

Wang, L., Liu, S., Zhao, Y., Liu, D., Liu, Y., Chen, C., . . Jin, Y. (2015). Osteoblastinduced osteoclast apoptosis by fas ligand/FAS pathway is required for maintenance of bone mass. Cell Death and Differentiation, doi:10.1038/cdd.2015.14 [doi]

Yang, I. V., Pedersen, B. S., Liu, A., O'Connor, G. T., Teach, S. J., Kattan, M., . . . Schwartz, D. A. (2015). DNA methylation and childhood asthma in the inner city. The Journal of Allergy and Clinical Immunology, 136(1), 69-80.

doi:10.1016/j.jaci.2015.01.025 [doi] 
Yi, K. D., \& Simpkins, J. W. (2008). Protein phosphatase 1, protein phosphatase 2A, and calcineurin play a role in estrogen-mediated neuroprotection. Endocrinology, 149(10), 5235-5243. doi:10.1210/en.2008-0610 [doi]

Yuan, T., Jiao, Y., de Jong, S., Ophoff, R. A., Beck, S., \& Teschendorff, A. E. (2015). An integrative multi-scale analysis of the dynamic DNA methylation landscape in aging. PLoS Genetics, 11(2), e1004996. doi:10.1371/journal.pgen.1004996 [doi]

Zhang, J., Chen, X., Zhang, S., Zhou, G., Xia, X., \& Lu, L. (2009). Effects of transdermal estrogen therapy on expressions of estrogen receptors and T-lymphocyte apoptosis in surgically menopausal women. Cellular \& Molecular Immunology, 6(4), 277-283. doi:10.1038/cmi.2009.37 [doi] 


\section{$\underline{\text { Tables }}$}

Table 1. General properties and metabolic measures of the HRT discordant MZ twin pairs in the study.

\begin{tabular}{|c|c|c|c|}
\hline Measure & $\begin{array}{l}\text { HRT users } \\
\quad \mathbf{N}=\mathbf{2 0}\end{array}$ & $\begin{array}{l}\text { Non-users } \\
\quad \mathbf{N}=\mathbf{2 0}\end{array}$ & $\begin{array}{l}\text { Within-pair } \\
\text { difference } \\
\text { (p-value) }\end{array}$ \\
\hline \multicolumn{4}{|l|}{ General properties } \\
\hline Time of HRT use (in years) & $8.8 \pm 5.7$ & never & \\
\hline $\mathrm{E}_{2}$ treatment (\# of users) & 12 & none & \\
\hline Combined treatment (\# of users) & 8 & none & \\
\hline Mean physical activity score & $2.55 \pm 0.6$ & $2.55 \pm 0.6$ & \\
\hline $\begin{array}{l}\text { (\# of active/moderately } \\
\text { active/sedentary) }\end{array}$ & $(12 / 7 / 1)$ & $(12 / 7 / 1)$ & \\
\hline \multicolumn{4}{|l|}{ Smoking status } \\
\hline Smoker while co-twin is non-smoker & 3 & 2 & \\
\hline Both non-smokers & \multicolumn{3}{|c|}{11} \\
\hline Both smokers & \multicolumn{3}{|c|}{4} \\
\hline \multicolumn{4}{|l|}{ Blood cell count estimates } \\
\hline CD8 T cells & $-8.7 \times 10^{-20} \pm 3.9 \times 10^{-19}$ & $0.001 \pm 0.002$ & 0.18 \\
\hline CD4 T cells & $0.141 \pm 0.007$ & $0.139 \pm 0.007$ & 0.23 \\
\hline NK cells & $0.261 \pm 0.007$ & $0.261 \pm 0.006$ & 0.96 \\
\hline $\mathrm{B}$ cells & $0.210 \pm 0.004$ & $0.210 \pm 0.006$ & 0.76 \\
\hline Monocytes & $0.072 \pm 0.006$ & $0.073 \pm 0.004$ & 0.35 \\
\hline Granulocytes & $0.211 \pm 0.006$ & $0.211 \pm 0.004$ & 0.78 \\
\hline \multicolumn{4}{|l|}{ Serum hormones } \\
\hline$\overline{\mathrm{E}_{2}, \mathrm{pmol} / \mathrm{l}}$ & $202.8 \pm 205.8$ & $27.1 \pm 22.0$ & $9.6 e-05$ \\
\hline Free $E_{2}, \mathrm{pmol} / \mathrm{l}$ & $3.5 \pm 2.9$ & $0.6 \pm 0.5$ & $9.5 \mathrm{e}-06$ \\
\hline $\mathrm{SHBG}, \mathrm{nmol} / \mathrm{l}$ & $86.2 \pm 41.3$ & $55.3 \pm 27.1$ & $3.6 e-05$ \\
\hline \multicolumn{4}{|l|}{ Blood lipids and CRP* } \\
\hline Total cholesterol, $\mathrm{mmol} / \mathrm{l}$ & $5.3 \pm 0.5$ & $5.3 \pm 0.4$ & 0.82 \\
\hline LDL cholesterol, mmol/l & $3.1 \pm 0.8$ & $3.2 \pm 0.4$ & 0.91 \\
\hline HDL cholesterol, mmol/l & $1.6 \pm 0.5$ & $1.5 \pm 0.4$ & 0.23 \\
\hline Triglycerides, mmol/1 & $1.2 \pm 1.0$ & $1.1 \pm 0.5$ & 0.48 \\
\hline High sensitivity CRP, mg/l & $1.2 \pm 1.0$ & $1.2 \pm 0.9$ & 0.91 \\
\hline
\end{tabular}

$*$ Variables of blood lipids and CRP were available from 9 twin pairs. $\mathrm{E}_{2}=17 \beta$-estradiol, $\mathrm{CRP}=\mathrm{C}$ reactive protein, $\mathrm{LDL}=$ low density lipoprotein, $\mathrm{HDL}=$ high density lipoprotein. 
Table 2. Phenotype characteristics of the MZ twin pairs in the study.

\begin{tabular}{|l|cc|c|}
\hline Measure & HRT twins & Non-HRT twins & $\begin{array}{c}\text { Within-pair } \\
\text { difference (p-value) }\end{array}$ \\
\hline Body composition & $23.3 \pm 8.0$ & $26.5 \pm 10.3$ & 0.074 \\
Fat percentage & $47.6 \pm 3.5$ & $47.6 \pm 4.3$ & 0.87 \\
Lean body mass, kg & & & \\
& & & 0.25 \\
Thigh muscle characteristics* & $9597.8 \pm 1123.7$ & $9124.4 \pm 1442.8$ & 0.29 \\
Lean muscle CSA & $1540.6 \pm 700.0$ & $1816.3 \pm 1066.7$ & 0.34 \\
IM fat CSA & $55.3 \pm 3.7$ & $55.6 \pm 5.5$ & 0.080 \\
Lean muscle density & $7658.9 \pm 3255.2$ & $9794.9 \pm 6091.2$ & \\
Subcutaneous fat & & & 0.0046 \\
& & & 0.018 \\
Bone BMC, mg/mm & $274.2 \pm 35.9$ & $254.3 \pm 48.0$ & \\
Distal tibia & $104.0 \pm 15.2$ & $96.2 \pm 20.3$ & \\
Distal radius & &
\end{tabular}

*Variables of thigh muscle characteristics were available from 9 twin pairs. ${ }^{\$}$ Distal tibia was measured from 8 twin pairs. ${ }^{£}$ Distal radius was measured from 9 twin pairs. $C S A=$ cross-sectional area, $\mathrm{IM}=$ intra/intermuscular, $\mathrm{BMC}=$ bone mineral content. 
Table 3: Differentially methylated GO terms from the Gene Set Analysis (GSA) of HRT-discordant MZ twin pairs.

\begin{tabular}{|c|c|c|c|c|c|c|}
\hline & GO term & Ontology & Genes & Score & P-value & FDR \\
\hline \multirow{3}{*}{$\begin{array}{l}\text { Hypomethylated } \\
\text { in HRT }\end{array}$} & $\begin{array}{c}\text { Formation of } \\
\text { translation } \\
\text { preinitiation complex }\end{array}$ & $\mathrm{BP}$ & DENR, EIF2D, EIF3A-B, EIF3D-H, EIF3J, EIF3LM, TICRR & -0.49 & $<2.2 \times 10^{-16}$ & $<2.2 \times 10^{-16}$ \\
\hline & $\begin{array}{c}\text { Negative regulation of } \\
\text { apoptotic signaling } \\
\text { pathway }\end{array}$ & $\mathrm{BP}$ & $\begin{array}{c}B A X, B C L 2, B M F, C T H, C T N N B 1, F A I M 2, M A D D, M A P 3 K 7, M E I S 3, \\
\text { MKL1, MNT, NANOS3, NOG, PCGF2, PSEN1, WNT4 }\end{array}$ & -0.35 & $<2.2 \times 10^{-16}$ & $<2.2 \times 10^{-16}$ \\
\hline & $\begin{array}{c}\text { Eukaryotic } 43 \mathrm{~S} \\
\text { preinitiation complex }\end{array}$ & $\mathrm{CC}$ & EIF3A-B, EIF3D-H, EIF3J, EIF3L-M & -0.35 & $<2.2 \times 10^{-16}$ & $<2.2 \times 10^{-16}$ \\
\hline \multirow[b]{3}{*}{$\begin{array}{l}\text { Hypermethylate } \\
\text { d in HRT }\end{array}$} & $\begin{array}{l}\text { Sphingolipid } \\
\text { metabolic process }\end{array}$ & $\mathrm{BP}$ & $\begin{array}{c}\text { ACER1-3, ALOX12B, ALOXE3, ARSA-B, ARSG, ARSI-K, ASAH1-2, CERK, } \\
\text { CERS2-6, CSNK1G2, CTSA, DBP, DEGS1-2, ENPP7, FA2H, GAL3ST1, } \\
\text { GALC, GBA, GBA3, GLB1, GM2A, HES7, HEXA-B, KDSR, NEU2-4, } \\
\text { PPAP2A-C, PPM1L, PRKD1, PSAP, SERINC1-3, SERINC5, SFTPB, } \\
\text { SGMS1-2, SGPL1, SGPP1-2, SMPD1, SMPD3, SPHK1-2, SPNS2, SPTLC1- } \\
\text { 3, SUMF1, TEX2, TH, UGCG, VAPA-B }\end{array}$ & 0.21 & $<2.2 \times 10^{-16}$ & $<2.2 \times 10^{-16}$ \\
\hline & $\begin{array}{l}\text { Ceramide metabolic } \\
\text { process }\end{array}$ & $\mathrm{BP}$ & $\begin{array}{c}\text { ACER2-3, ASAH1-2, CERK, CLN3, CLN8, NSMAF, ORMDL1, ORMDL3, } \\
\text { PLA2G15, PPP2CA, PPP2R1A, SGPL1 }\end{array}$ & 0.52 & $<2.2 \times 10^{-16}$ & $<2.2 \times 10^{-16}$ \\
\hline & $\begin{array}{l}\text { Detection of chemical } \\
\text { stimulus involved in } \\
\text { sensory perception of } \\
\text { smell }\end{array}$ & $\mathrm{BP}$ & 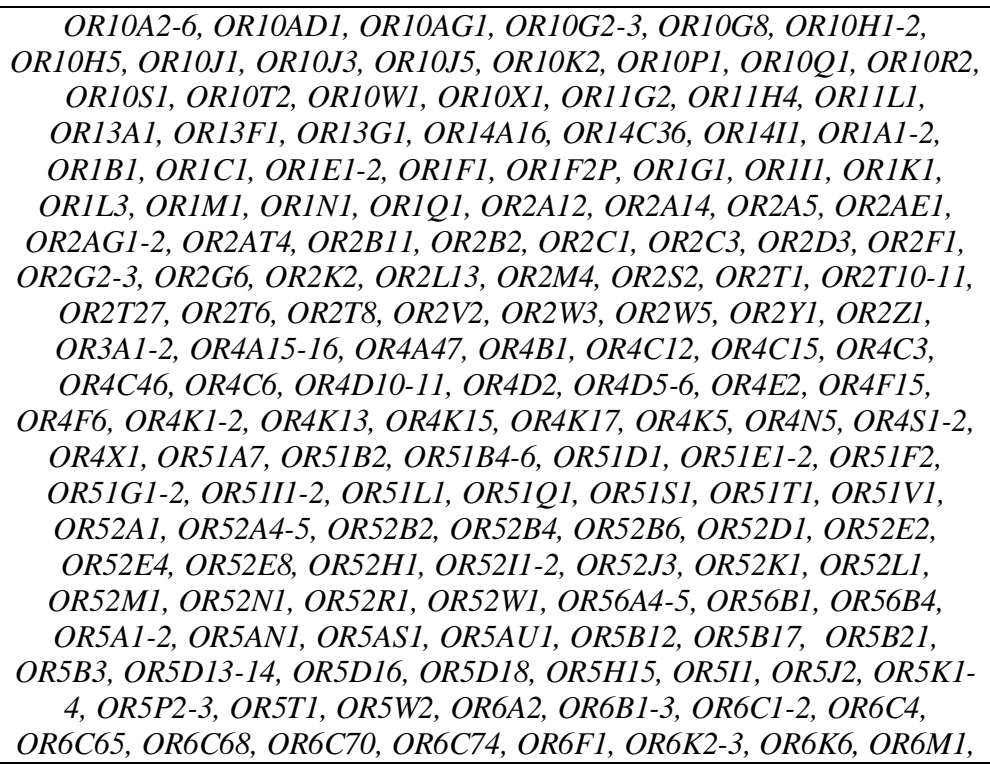 & 0.23 & $<2.2 \times 10^{-16}$ & $<2.2 \times 10^{-16}$ \\
\hline
\end{tabular}




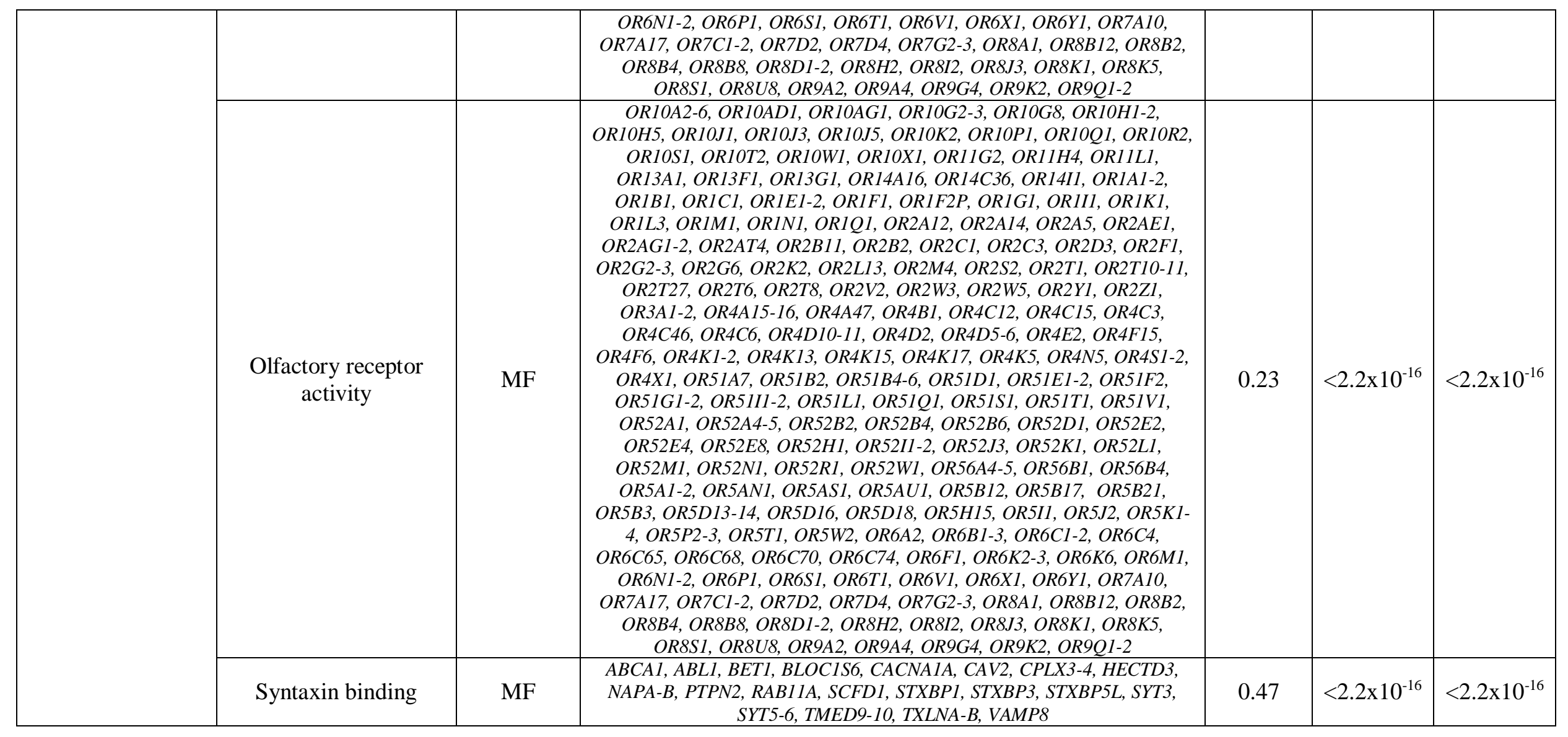


Table 4. Differentially expressed genes with DMRs within HRT discordant twin pairs.

\begin{tabular}{|c|c|c|c|c|c|}
\hline $\begin{array}{c}\text { Expression } \\
\text { probe }\end{array}$ & DMR & $\begin{array}{c}\text { Gene } \\
\text { symbol }\end{array}$ & $\begin{array}{c}\text { Expression } \\
\text { Log FC* }\end{array}$ & P-value & FDR \\
\hline ILMN_1766054 & cg13430450 & $A B C A 1$ & -0.281 & $2.4 \times 10^{-07}$ & 0.0016 \\
\hline ILMN_1773352 & $\begin{array}{c}\text { IC_cg10315334 } \\
\text { and } \\
\text { cg12455187 }\end{array}$ & CCL5 & 0.144 & $1.1 \times 10^{-06}$ & 0.0026 \\
\hline ILMN_1786065 & $\begin{array}{c}\text { IC_cg14759209/ } \\
\text { cg23867903 }\end{array}$ & UHRF1 & -0.135 & $6.7 \times 10^{-06}$ & 0.0060 \\
\hline ILMN_1660732 & cg19494588 & PPP2R2B & 0.138 & $2.8 \times 10^{-05}$ & 0.020 \\
\hline ILMN_1781824 & cg10161121 & FASLG & 0.145 & $6.3 \times 10^{-05}$ & 0.036 \\
\hline
\end{tabular}

*Negative log fold change denotes downregulation and positive log fold change upregulation in the HRT using co-twins compared with their non-using co-twins. Log fold changes as well as associated p-values and FDRs result from the candidate gene expression analysis in which only genes with DMRs were considered. DMR, differentially methylated region; FC, fold change. 


\section{Figure legends}

Figure 1. Genomic distribution of the DMRs in relation to genes and CpG density. Bar plots show the proportions of the DMRs at genes and intergenic regions (a), and at $\mathrm{CpG}$ islands and non-island $\mathrm{CpGs}(\mathrm{b}) . \mathrm{P}$ values denote which of the $\mathrm{CpG}$ categories are over- or underrepresented among the DMRs $(n=7855)$ in the HRT discordant twin pairs. Fisher's exact test was used to determine under- or overrepresentation of the CpG categories among the DMRs. Promoters include CpGs at 5'UTRs, CpGs <1500bp from transcription start site, and at 1st exon. $\mathrm{HC}, \mathrm{CpGs}$ at high density $\mathrm{CpG}$ island, IC; CpGs at intermediate density $\mathrm{CpG}$ island; $\mathrm{LC}$, non- $\mathrm{CpG}$ island $\mathrm{CpG}$ sites; *, FDR<0.01; **, $\operatorname{FDR}<3.3 \times 10^{-16}$

Figure 2. DMR patterns were unique for each of the identified differentially expressed genes with DMRs. Genes are split up into three genomic locations: promoter, gene body and 3' UTR. The position of the indicated DMR shows the genomic location in which it appears in the given gene, the tag above gives its location in relation to $\mathrm{CpG}$ density. Bold solid black line under the tag indicates hypermethylation and thin gray dotted line hypomethylation. LC refers to low density and IC intermediate density $\mathrm{CpG}$ island. No differentially expressed genes with high density $\mathrm{CpG}$ island was found. The differential expression is indicated by arrows. Solid black arrows indicate higher and thin dotted gray arrows lower expression in HRT users compared to non-users, respectively.

Figure 3. Heat map of correlations between significantly differentially expressed genes with DMRs and clinical measures. The heat map shows genes on the $\mathrm{x}$-axis and clinical measures on the y-axis. Colors of squares in the heat map indicate correlation values (see color key). Dark red squares stand for high negative correlations between gene and trait, dark blue squares indicate strong positive correlations. Stars in the squares indicate 
significant p-values $(*)$ and FDRs $(* *)$ with 0.05 as cut-off, respectively. The dendrogram on the left-hand side shows clustering of the clinical measures, the one above the heatmap shows clustering of the genes according to the similarity of their correlation profiles.

Supplementary Material is available on the Cambridge Journals Online website. 